\title{
Comparative analysis of the Serbian and German legislation on emergency medical services
}

\begin{abstract}
The political developments in Serbia and the hostilities and economic sanctions of the nineties resulted in a significant deterioration of the economy. These circumstances gave rise to damage to and neglect of the infrastructure, as well as of the administrative structure of the country. Hence, it is not surprising that the present population health standard of Serbia is, although similar to other central and eastern European countries, still below that of western Europe. In view of this background, the article will firstly describe the present Serbian legislation on emergency medical services. Subsequently, it comments on the German legislation on emergency medical services as an exemplar of the respective regulation of a western European state. Based on these descriptions and with reference to EU legal standards, a comparison between the two legislations is drawn. The article concludes with recommendations for possible improvements to the Serbian legislation on emergency medical services.
\end{abstract}

Keywords: EU accession, emergency medical services, legislation, health insurance systems, quality criteria in health care, continuing training, professional specialisation, competences of EU, standardisation in EU

\section{Introduction}

Serbia is currently in a phase of pre-accession to the EU. This indeed necessitates, but then also accelerates, an approximation towards western European standards. At present, Serbia is rebuilding its economy and infrastructure. Furthermore, it is implementing an extensive programme of decentralisation. The measures emerging alongside this process of rapid transition have an influence on all sectors of government and civil society. In particular, legislation is being adapted to meet new national priorities, including harmonisation with EU norms and standards. With regard to the health sector, the Serbian government has made its reform a national priority. The ministry of health prepared a Strategy and action plan for health care reform in early 2003. The reform of primary health care in particular was cited as a high priority reform by the Decree on the network plan for health institutions (2006). This might inter alia have been caused by the results of several reviews and assessments which were carried out to support health care reform. The outcomes of these mainly indicated the need for improvements in the range of emergency medical services as a part of primary health care. Some areas, such as knowledge, skills, team work capacities and emergency procedures, were assessed as lower than the standards of the EU. It was further suggested that the approach to emergency care should be more systematic. 


\section{Serbian legislation on emergency medical services}

The Serbian legislation regulating the emergency medical services (EMS) is found in legal provisions at different levels and is, therefore, quite fragmented. The Health Care Law as well as the Health Insurance Law form the legal basis and these define the functioning and organisation of EMS in Serbia.

Moreover, there are several subordinated regulations, such as the Network plan for health institutions, the Rule book on the conditions and the means of internal organisation of health institutions or the Rule book on detailed conditions for the performance of health activities in the health institutions and other forms of health services. These regulate the structure of health care units as well as the medical personnel required for the performance of emergency medical care (EMC). The Rule book on the content and scope of rights to health care lists, among other issues, the health care services which should be provided in emergency medical cases as well as their scope. In addition, the Rule book on the quality criteria and methodology explanation for the procedures of reporting by health institutions on the mandatory quality criteria of health care prescribes, amongst others, the quality criteria which should be followed when performing EMC at primary, secondary and tertiary levels of health care. The Rule book on the practical training and the expert examination of health workers and medical associates and the Rule book on specialisation and advanced specialisation of health workers and medical associates regulates the education and training of health care workers in different areas of health care, including EMC. There is also a codex of professional ethics defining the rights of patients and the duties of physicians.

The number of regulations regarding EMS emphasises the great importance which is basically attached to this issue. In order to prove whether the respective provisions meet the demands one should made of an efficient EMS, the particular regulations are examined more closely in the next few sections.

Health care law

As mentioned before, the Health Care Law (HCL) is the legal foundation of EMS in Serbia. It regulates the different ways of performing EMS and how this is organised. These issues are not laid down in one place but can be found in the following provisions of the HCL.

\section{Obligation to provide emergency medical care}

In its introductory provisions within the chapter 'Social care for the health of the population', the HCL obliges not just EMS units to provide EMC, but also the whole society. By this, it means the Republic of Serbia, by providing financial coverage from the health insurance or budgetary resources (Art. 11, HCL; Article 22, Health Insurance Law (hereinafter HIL); and Article 23 of the Rule book on the content and scope of rights to health care covered by health insurance financial resources and on co-payment for 2009); employers, by providing first aid in the case of industrial injury and by providing conditions for EMC (Art. 14, prov. 1, bullet 12, HCL); and individuals, by providing first aid, as well as accessibility to the EMS unit to injured or ill people in urgent cases and within the limits of their own knowledge and possibilities. 
Special relevance of emergency medical services assigned by the health care law

The HCL regulates the right of the patient to self-determination and consent but, in some cases, it allows that EMS can be performed even without the patient's consent. This applies if the patient is unconscious or cannot give consent for other reasons (Art. 34, HCL).

Within the process of medical treatment, patients have not only rights but duties as well. They have to participate actively in the protection, preservation and improvement of their health, and appraise competent health workers of full information of their state of health, as well as follow the instructions and undertake the measures of therapy prescribed by the health worker in charge. Should the patient fail to adhere to these obligations, the physician may refuse any further provision of health care to the patient except for emergency medical care (Art. 43, HCL).

During standby hours, a doctor on call must, even though s/he does not have to be present in the health care facility, be constantly available for the purpose of providing emergency medical care (Art. 78, prov. 3 HCL).

According to Article 171 of the HCL, a health worker can reject the provision of health care if this is not in accordance with his or her conscience or within the international rules of medical ethics. This rejection is called conscientious objection. However, $\mathrm{s} /$ he may not refuse to provide emergency medical care by expressing conscientious objections.

\section{Organisation of emergency medical services}

As regards the organisation of EMS units, Art. 47, prov. 3 of the HCL refers to the Network plan for health institutions (the Network Plan). The HCL still provides the general framework for the organisation of EMS. Pursuant to Art. 56 of the HCL, health care providers in Serbia are generally divided into health institutions and private practices, but only health institutions are allowed, under certain conditions, to perform EMS as a health activity.

\section{a) Health institutions}

A health institution is a health care facility that is engaged in healthcare activity at the primary level and provides health care to certain groups of the population or, otherwise, healthcare activity in certain areas of health care (Art. $102 \mathrm{HCL}$ ).

\section{i) Institute for Emergency Medical Care}

Art. 105 of the HCL defines the Institute for Emergency Medical Care (IEMC) as the health institution at the primary level of health care which performs EMC as well as carrying out the medical transport of acutely ill and injured people to other appropriate health institutions, the transport of patients on dialysis and the provision of medicines administered in emergency cases.

ii) Primary health care centre

The Primary Health Care Centre (PHCC) is a health institution which performs health activities at the primary level of health care (Art. $94 \mathrm{HCL}$ ). Art. 95 of the HCL defines the PHCC, or Dom Zdravlja, as the health institution providing, inter alia, EMC. It also 
provides ambulance transport if that service is not organised from within a hospital or another health care facility in the territory for which the PHCC has been founded (Art. 95 prov. $3 \mathrm{HCL}$ ).

iii) Local clinic

A PHCC may not be accessible to the whole Serbian population, so there are possibilities to establish healthcare outpatient units and local clinics in accordance with the Network Plan. A local clinic is a unit of the PHCC which performs at least EMC, general medicine and paediatrics (Art. $97 \mathrm{HCL}$ ).

b) Private practice

According to Art. 56, prov. 6 of the HCL, a private practice is not allowed to perform or engage in EMS activity. In compliance with Art. 62 of the HCL, a private practice is, all the same, obliged to provide urgent medical help to citizens when needed.

Decree on the network plan for health institutions

The Decree on the network plan for health institutions ${ }^{1}$ defines the number, structure, capacities and space disposition of public health institutions. It further regulates their organisational units per level of health care and the organisation of the EMC units, as well as other important issues related to health service organisation.

Following the structure of the HCL, the Network plan establishes the EMC being organised within two functionally linked sub-systems: pre-hospital emergency medical care; and in-patient emergency medical care (Arts. 32-35 Network Plan).

\section{Pre-hospital emergency medical care}

Pre-hospital EMC is the continuous activity of health institutions at the primary health care level. It encompasses the provision of medical care at the point of injury/illness and in the health institution, the medical transport of severely ill and injured people to medical institutions and the continuous monitoring of health and the provision of necessary help during transport.

a) Primary health care centre

In municipalities with over 25000 inhabitants, pre-hospital EMC is performed in the PHCC. Essentially, it is one part of the regular activity of the physician and his or her associates but at night, on Sunday and during state holidays, pre-hospital EMC forms part of the work of the physician on call (Art. 34 Network Plan).

b) Branch and local clinic

Depending on the number of inhabitants, the PHCC can establish outside units. These are the branch, the local clinic and the healthcare outpatient unit - depending on the number of inhabitants allocated in that particular area. Branches and local clinics perform the types of EMC that healthcare outpatient units do not (Art. 7 Network Plan).

1 Official Gazette RS No. 42/2006, 119/2007 and 84/2008. 
c) Institute for emergency medical care

EMC at the primary level is also performed by the IEMC - at the place of accidents, during transport and within the health institution.

\section{In-patient emergency medical care}

In-patient EMC is provided by expert teams of the acknowledged accident and emergency units of general hospitals, ${ }^{2}$ clinics, ${ }^{3}$ institutes, ${ }^{4}$ clinical hospitals ${ }^{5}$ and clinical centres $^{6}$ in the case of admission for hospital treatment.

\section{Rule book on the detailed conditions for the performance of health activities in health institutions and other forms of the health service}

The Rule book ${ }^{7}$ on the detailed conditions for the performance of health activities in health institutions and other forms of the health service ${ }^{8}$ (Rule book on detailed conditions) defines the detailed conditions related to personnel, equipment, facilities and medicine which need to be fulfilled by health institutions in order to perform health care activities.

\section{Medical personnel in the primary health care centre}

Depending on the number of inhabitants in the area that must be covered, and depending on the distance to the nearest general hospital, a PHCC is qualified - if it has a certain number of personnel - to perform its activities. As regards EMC, the PHCC must have one medical doctor, one medical associate graduating from advanced or secondary school and one driver per 6000 inhabitants. The second team requires one medical doctor, two medical associates of the same educational level and one driver (Art. 4, prov. 1, bullet 5 Rule book on detailed conditions).

2 A hospital is a health care facility that is engaged in health care activity at the secondary level (Art. 110 prov. $1 \mathrm{HCL}$ ). A general hospital shall provide health care to people of all ages suffering from different kinds of diseases (Art. 111 prov. $1 \mathrm{HCL}$ ).

3 A clinic is a health care facility that is engaged in highly specialised specialist and consulting and inpatient health care activity within a certain branch of medicine, or dentistry (Art. 115 prov. $1 \mathrm{HCL}$ ).

4 An institute - centre of excellence - is a health care facility that is engaged in highly specialised specialist and consulting and inpatient healthcare activity, or only highly specialised specialist and consulting healthcare activity in one of several branches of medicine or dentistry (Art. 116 prov. $1 \mathrm{HCL}$ ).

5 A clinical hospital is a health care facility that is engaged in highly specialised specialist and consulting and in-patient healthcare activity at the tertiary level in one or several branches of medicine (117 prov. $1 \mathrm{HCL}$ ).

6 A clinical centre is a health care facility that unifies the activities of three or more clinics in such a way that it makes up one functional unity, organised and capable of successfully administering the affairs of and carrying out the tasks related to: 1) engaging in highly specialised specialist and consulting and inpatient healthcare activity; 2) educational and teaching activities; 3) scientific and research activity (Art. 118 prov. $1 \mathrm{HCL}$ ).

7 A Rule book is a bylaw.

8 Official Gazette No. 46/2006. 


\section{Medical personnel in the Institute for Emergency Medical Care}

The IEMC can be established and is permitted to carry out its tasks if it has the following personnel: it must have at least one medical doctor, seven medical associates graduating from advanced or secondary school and one driver per 6000 inhabitants. As regards medical transport, the IEMC needs one additional driver per every 15000 inhabitants (Art. 12, prov. 2 Rule book on detailed conditions). There must also be a pharmacist for pharmaceutical health activities (Art. 12, prov. 3 Rule book on detailed conditions).

\section{Medical personnel in a general hospital}

A general hospital has, in the department for admittance and the care of urgent cases, one medical specialist and four medical associates graduating from advanced or secondary school (including one laboratory and one radiologist technician) per 100 hospital beds.

In-patient institutions which cannot sufficiently take care of ill or injured patients are obliged to provide medical transport and adequate expert assistance during transport to an appropriate in-patient institution (Arts. 32-35 Network Plan).

\section{List of equipment}

The Rule book on detailed conditions also prescribes a list of the equipment needed for the conduct of health activities within certain health areas. Thus, the list also outlines the necessary equipment for EMC in the PHCC as well as in the IEMC. The list of equipment further comprises separate lists for the admissions department; the department for interventions and reanimations; standard and special medical vehicles; and the centre for despatching medical vehicles.

Health Insurance Law and Rule book on the means and procedure of the realisation of rights stemming from mandatory health insurance

The Health Insurance Law ${ }^{9}$ (HIL) regulates which rights are guaranteed by the mandatory health insurance of employees and other citizens. It further determines the organisation and financing of mandatory health insurance, voluntary health insurance and other issues important to the health insurance system.

The Rule book on the means and procedure of the realisation of rights stemming from mandatory health insurance ${ }^{10}$ regulates how insured people can realise their rights, the conditions that must be fulfilled in return and the way in which they may make use of health care and other rights deriving from mandatory health insurance.

\section{Special relevance of emergency medical services assigned by the Health Insurance Law}

In order to be able to use the rights offered by the financial resources of the health insurance fund, the insured party has to be insured for a certain period of time (a continuous period of at least three months, or six months overall within eighteen months).

10 Official Gazette RS No. 24/2009. 
There are very few exceptions to this rule under which patients can assert rights to health care covered by mandatory insurance even if they were not insured for the relevant period of time; one of these exceptions is the need for EMC (Art. $32 \mathrm{HIL}$ ). The other condition for asserting rights to health care offered by the financial resources of health insurance is that all health insurance contributions have to be paid; the only exception to this rule is, again, where the respective party requires EMC (Art. 142 HIL).

The HIL adjudicates a great value to EMC at many other points. For example, it prescribes the percentages up to which certain health services are covered by the financial resources of health insurance. According to Article 45, prov. 1, bullet 9, EMC is covered up to $100 \%$ (see also Art. 20 of the Rule book on the content and scope of rights to health care covered by health insurance financial resources and on co-payment for 2009).

What is more, pursuant to Article $183 \mathrm{HIL}$, the Health Insurance Fund (HIF) covers health care services only if they are rendered by contractual health care providers. Health care services which are not performed by contractual health care providers are only covered by HIF if they rank among EMC.

Moreover, insured parties who are abroad must be aware that only EMC is covered by the mandatory health insurance funds (Art. 63 and Art. 64), including the necessary medical devices and implants (Art. 71). Other services which do not come under EMC are not covered by the mandatory health insurance funds.

Furthermore, insured parties can generally realise their right to health care in health institutions located on the territory of the HIF branch office with which they are registered. When they are outside this territory, they can do this only in exceptional cases; one exceptional case is the appearance of an urgent medical case (Art. 43 Rule book on the means and procedure of the realisation of rights stemming from mandatory health insurance).

\section{Definition of emergency medical care}

The right to EMC is one of the rights to health care covered by the resources of the health insurance fund (Art. 37 and Art. 41 HIL). Pursuant to Article 53 HIL, EMC constitutes direct and prompt medical help provided in order to avert danger to the life of the insured party, i.e. irreversible or serious weakness or damage to health, as well as death.

Rule book on the content and scope of rights to health care covered by health insurance financial resources and on co-payment for 2009

At first, the Rule book on the content and scope of rights to health care covered by health insurance financial resources and on copayment for $2009^{11}$ defines EMC in the same way as the HIL. However, it further regulates EMC to be medical care which is rendered within twelve hours of the moment of admission of the insured party to the health institution. Thereby, the possibly expected origination of urgent medical conditions may be avoided. 
The scope of health care in emergency medical cases should be in accordance with the needs of the ill/injured insured party, i.e. in accordance with the intensity of the threat to health caused by injury, illness or other health disturbances.

At the place of injury or illness, health care in emergency medical cases encompasses first aid, physical examination, medical treatment and drug therapy as well as transport.

In health institutions, health care in emergency medical cases constitutes first aid, physical examination, the necessary diagnostic and laboratory examinations, medical treatment and appropriate care, as well as therapy treatment.

Rule book on the quality criteria for health care and the Methodological explanation for the reporting procedures of health care institutions on the mandatory quality criteria for health care

The Rule book on the quality criteria for health care ${ }^{12}$ regulates the quality features under which health care must be carried out. The Methodological explanation for the reporting procedures of health care institutions on the mandatory quality criteria for health care $^{13}$ (hereinafter, Methodology) defines the means of collecting, monitoring, accounting for and the reporting of quality criteria on the work of health workers.

The Rule book on the quality criteria for health care distinguishes between obligatory and recommended criteria for EMC at the primary, secondary and tertiary levels of health care (Arts. 19, 20 and 39 Rule book on the quality criteria for health care).

\section{Quality criteria at the primary level}

The mandatory criteria for primary health care are:

- Reaction time I - the period of time from call acceptance in the co-ordination centre to the handing of the call to the team in action

- Reaction time II - the time between call acceptance and the moment the team in action reaches the patient; the percentage of successful cardio-pulmonary reanimations; the percentage of sudden deaths in relation to the number of realised cardio-pulmonary reanimations; and the percentage of autonomously-solved cases at the place of injury/illness.

The recommended criteria for primary health care are:

- Reaction time III - the period of time from the arrival of the team in action at the patient's location to the end of the intervention

- Reaction time IV- the period of time from the arrival of the team in action at the patient's location to the handing over of the patient to further medical care; sensitivity at the call acceptance unit; specificity at the call acceptance unit; the percentage of medical treatment on the territory related to patients with serious trauma; the percentage of patients on the territory with acute coronary syndrome, and subject to intravenous interventions and who were given morphine, oxygen, nitrates and acetylsalicylic acid; the percentage of patients receiving medical care in the ambu-

13 Belgrade, 2007: Republic Institute for Public Health - Batut. 
lance station; the percentage of autonomously-solved cases at the ambulance station; the percentage of patients who received medical care on the territory; the existence of a written reaction plan for exceptional situations; and the existence of written protocols for the transport of patients.

The data required for evaluating the quality criteria are collected by the leader of each operational area for each operational area separately. Daily data are gathered in monthly forms which are, in turn, gathered into yearly forms. The yearly forms are forwarded to the Regional Institute for Public Health. The Regional Institute forwards the data to the Republic Institute for Public Health which then sends the report on the collected data to the Institute for Emergency Medical Care in Novi Sad. The Special Working Group for Urgent Medicine (SGUM) makes the final analysis which is, again, forwarded to the Republic Institute for Public Health.

\section{Quality criteria at the secondary and tertiary levels of health care}

The obligatory criteria for EMC in secondary and tertiary level health institutions constitute the percentage of urgent cases examined and taken care of within one hour of the moment of contacting a nurse or physician, and the percentage of successful cardiopulmonary reanimations.

One of the recommended characteristics in secondary and tertiary level health institutions is waiting time for examination from the point of admittance to the health care institution. The Methodology suggests that at least $90 \%$ of patients classified as urgent cases should be examined and taken care of within one hour of the first contact with a nurse or physician (the so-called 'golden hour'). Another recommended characteristic is the existence of written protocols for treating cases of serious trauma. In this regard, the Methodology advises that all patients who arrive for emergency hospitalisation should be estimated within thirty minutes of their arrival. This evaluation can be carried out by a physician or a triage nurse having adequate training.

Whether the emergency services of secondary and tertiary level institutions fulfil the quality requirements can be learned from patient protocols. Data, which are gathered in a form, are submitted annually to the Regional Institute for Public Health.

\section{Decision on the establishment of the Special Working Group for Urgent Medicine ${ }^{14}$}

The Special Working Group for Urgent Medicine has been established to carry out methodological, doctrinaire and consultative activities in the area of urgent medicine. The SGUM works within the Ministry of Health of the Republic of Serbia. It has the following tasks in particular:

- to make proposals for the national programme of urgent medicine in Serbia

- to propose legal regulations related to urgent medicine

- to define guidelines for guidebooks of good practice

- to prepare a programme of continuous education and to monitor the realisation of this programme in the relevant institutions 
- to prepare, propose and co-ordinate action plans and programmes for emergency situations

- to co-operate with the relevant foreign and international organisations for the purpose of exchanging knowledge.

Health care plan regarding mandatory health insurance in the Republic of Serbia in 2009

The purpose of the Health care plan regarding mandatory health insurance in the Republic of Serbia in $2009^{15}$ is to realise the right of insured parties to health care covered by mandatory health insurance within the available facilities and designated financial resources. This Plan therefore determines the health needs of insured parties at the primary, secondary and tertiary levels of health care and the available financial resources, depending on the sort and nature of the need. As for EMC, the Plan states that one has to expect an increase in the total number of services. This derives from recalling the growth of traffic accidents, the high level of chronic non-communicable mass diseases and other pathologies that require EMC.

Rule book on the conditions and the means of internal organisation of health institutions

Pursuant to the Rule book on the conditions and the means of the internal organisation of health institutions, ${ }^{16}$ the internal organisation of health institutions is determined in the context of levels of health care and types of health institution. Organisational units are formed depending on the sort of activity of the respective health institution, the scope of expert work, the facilities, the number of employees and other conditions.

Emergency medical care at the primary level of health care

$\mathrm{EMC}$ at the primary level of health care is organisationally performed in the PHCC and the IEMC.

a) Service of emergency medical care in a primary health care centre

Within the PHCC, there are three levels of organisational units divided on the basis of functional principles for certain activities. These three levels are: the service; the department; and the section.

A service is structured for one or more areas of health activities with at least ten health workers and medical associates; a department is organised with at least five health workers and medical associates; and a section has at least three health workers and medical associates. In compliance with Article 4 of the Rule book on the conditions

15 Official Gazette RS No. 8/2009. The Health care plan regarding mandatory health insurance in the Republic of Serbia in 2009 is based on Article 54 of the Health Insurance Act, according to which such a Plan is developed by the Managerial Board of the Republican Health Insurance Fund for each calendar year and approved by the Minister of Health.

Official Gazette RS No. 43/2006. 
and the means of internal organisation of health institutions, the PHCC can establish a unit for EMC as a service.

b) Service of emergency medical care in the Institute for Emergency Medical Care

Art. 12 Rule book on the conditions and the way of internal organisation of health institutions determines that the following organisational units can be formed within the Institute for EMC: the service for provision of EMC to acute ill and injured people, the departments or sections for answering the calls, for providing health care services in place, for ambulatory care for urgent cases, for pharmaceutical health activity, as well as for expert education and technical support, i.e. medical transport and vehicle service.

\section{Emergency medical care at the secondary level of health care}

EMC at the secondary level of health care is organisationally performed in a general hospital within the department for admittance and care for urgent conditions (Art. 21 Rule book on the conditions and the means of internal organisation of health institutions).

\section{Emergency medical care at the tertiary level of health care}

The Rule book on the conditions and the means of internal organisation of health institutions determines that EMC at the tertiary level of health care is performed within the department for admittance of various health institutions, i.e. in the clinic (Art. 30); in the institute (Art. 32); and in the clinical-hospital centre (Art. 34).

Rule book on the practical training and the expert examination of health workers and medical associates

The Rule book on the practical training and the expert examination of health workers and medical associates ${ }^{17}$ defines, among other issues, the plan and programme of practical training for health workers and medical associates.

A health worker is a person who has graduated from a faculty of medicine, dental medicine or pharmacy, or a person who has graduated from another medical school, who is directly engaged in a health care activity as a professional in a health care facility or private practice (Art. 165 prov. 1 HCL). A medical associate is a person with a secondary school, two-year post-secondary school or university qualification who is engaged in certain types of health care practice in a health care facility or private practice (Art. 165 prov. $2 \mathrm{HCL}$ ). Training means practical work under the respective supervision of competent health workers and medical associates.

Thus, health workers and medical associates may work autonomously under the supervision of mentors.

Knowledge or practice within the range of EMC activities is designated within the plans for different specialities. Thus, the provision of emergency medical care within health institutions, outside health institutions and during transport, as well as methods 
of medical care in the case of heart attack, cessation of breathing, acute intoxication, thermal shock, dehydration and burns, are essential parts of primary health care.

Paediatricians must be proficient in the principles of providing emergency medical care to injured and ill people within health institutions, outside institutions and during transport.

Other specialists, such as in internal medicine, gastroenterology, endocrinology, nephrology, haematology, gynaecology, surgery and obstetrics, must also be trained to take care of urgent cases in their specific area of specialisation.

Rule book on the specialisations and advanced specialisations of health workers and medical associates

The Rule book on the specialisations and advanced specialisations of health workers and medical associates ${ }^{18}$ regulates the different types of specialisations and advanced specialisations of health workers and medical associates with higher levels of education, the different programmes and the duration of the respective periods of education, as well as the way of performing special training and passing exams. Moreover, the Rule book determines the structure and work of the examination commissions and the conditions which should be fulfilled by health institutions in order that they be allowed to perform specialisation training, as well as other related issues.

It must further be pointed out that, according to the Rule book on the specialisations and advanced specialisations of the health workers and medical associates, medical doctors can specialise in the area of emergency medicine. This specialisation lasts four years (Art. 2, prov. 1, bullet 39; and prov. 2, bullet a). In the same way, specialists in general surgery can study further to specialise in emergency surgery (Art. 7, prov. 1, bullet 49).

\section{Codex of professional ethics of the Medical Chamber of Serbia}

The Codex of professional ethics of the Medical Chamber of Serbia ${ }^{19}$ (hereinafter, Codex) defines the ethical principles involved in the carrying out of professional duties in the Medical Chamber of Serbia, and the relationship between the members of the Medical Chamber and patients, as well as of the members of the Medical Chamber with each other.

In the area of EMS, the Codex mostly regulates the obligation of the physician to provide EMC to patients. In the case of danger to life, physicians are obliged to provide EMC within the scope of their possibilities and expert knowledge. They may not refuse to provide EMC which is correspondent with their expert abilities, regardless of whether or not they are on duty and regardless of whether or not they are explicitly asked for help. What is more, the physician has to be ready to help in exceptional circumstances and to keep up with the development, achievements and completion of know-

19 Official Gazette RS No. 121/2007. The Codex of professional ethics of the Medical Chamber of Serbia was enacted on the basis of Article 7 prov. 1 bullet 1 and Article 30 prov. 1 of the Law on Chambers of Health Professionals (Official Gazette RS No. 107/05) by the Assembly of the Medical Chamber of Serbia at its meeting on 28 September 2006. 
ledge and skills in providing EMC. He further has to be aware of the prevailing knowledge about work in states of emergency (Art. 6 Codex).

The physician also has to provide EMC to incapacitated people who have tried to commit suicide, notwithstanding either their will or their active or passive resistance (Art. 30 Codex). In the event of a hunger strike, the physician is obliged to provide EMC from the moment the hunger striker becomes confused and is unable to make decisions, or falls into a coma (Art. 33 Codex).

However, before physicians are allowed to intervene medically, they must await, as a basic principle, the consent of the fully-informed patient. Only in emergency situations can a physician provide medical care without the patient's consent (Art. 45 Codex).

Should a patient not comply with his or her responsibilities, the physician can stop treatment unless the health status of the patient requires EMC (Art. 52 Codex). He can further refuse provision of treatment if the patient is not satisfied with the physician's work or if he or she believes the physician to be insufficiently skilled or not to have the technical possibilities for successful treatment. Nevertheless, this does not apply to emergency situations (Art. 53 Codex).

\section{Concluding statement}

The number of laws and bylaws referring to EMS show that emergency medicine is an essential part of the Serbian health system. Nevertheless, there is neither a separate law on EMS nor a separate chapter concerning EMS alone within one of the relevant laws mentioned above. This confusion, deriving from the multitude of single provisions regarding EMS, makes it difficult to obtain an overview of the issue. One therefore cannot easily figure out how EMS is organised, which health institution is responsible for providing EMC in a particular case of emergency and which requirements must be complied with in order to be allowed to render EMS. This would indeed be necessary prior to calling EMS in Serbia well-functioning and efficient.

\section{German legislation on emergency medical services}

The German legislation on EMS is very detailed and it thus exemplifies a sophisticated framework for providing EMS.

In accordance with Articles 30 and 70 of the Grundgesetz (Basic Law - the Constitution of the Federal Republic of Germany, hereinafter GG), the federal states (Bundesländer) have legislative competence for the organisation and enforcement of EMS. For this purpose, every federal state has enacted its own law on EMS (Rettungsdienstgesetz). ${ }^{20}$ These laws should guarantee a nationwide EMS appropriate to the requirements in the respective federal state. A further aim is to preserve medical standards without levying unbearable fees on the people concerned. The respective laws cover questions of function, sponsorship, enforcement and organisation, the facilities of the

20 A register of every law on EMS in the Federal Republic of Germany is available at http:// www.bgs-aelrd.de/html/rettungsdienstgesetze_der_land.html [last accessed on 15 April 2009]. 
EMS, approval procedures and the duties of entrepreneurs, as well as the funding of the EMS. The federal states have implementing regulations which supplement these laws. Infringements of several provisions of the laws on EMS constitute regulatory offences.

The federal state laws on EMS do not exclude emergency facilities sponsored by private supporting organisations. In this case, the general rules of the civil law apply. ${ }^{21}$

According to Article 74 section 1 number 19 of the GG, the German Federation (Bund) has legal competence for the accreditation of medical and other health care professions. With regard to EMS, the German Federation enacted a law on emergency medical technicians regulating the apprenticeship required to achieve this job title (German Paramedic Act (Rettungsassistentengesetz), hereinafter RettAssG). ${ }^{22}$ This Law has been amended by a regulation covering education and assessments (Rettungsassistenten Ausbildungs- und Prüfungsverordnung, hereinafter RettAssAPrV). ${ }^{23}$

\section{Importance of the emergency medical services}

Everyone is in danger of falling into an emergency situation as a result of acute illnesses or accidents. Additionally, some people will need to be reliant on special aids or professional support during their trip to medical practices and clinics. In these cases, EMS provides citizens with qualified medical care in terms of their initial treatment (Erstversorgung) and in terms of providing professional ambulance services (Krankentransporte).

In the Federal Republic of Germany, EMS (Rettungsdienst) are services of a public interest character and constitute a medical-organisational and economic unit of health care and emergency management. Medical services by doctors on call (Notarztdienst) are an integral part of EMS. ${ }^{24}$

The main focus of EMS is on medical attendance on an emergency patient at a particular place and during transport to a convenient facility for further medical care. In this context, the chain of survival (Rettungskette) is of great importance, constituting the continuous and consequent care of an emergency patient up to admission to an appropriate facility. Elements in the chain of survival are: help from a lay person by means of immediate life-saving measures and first aid; announcement of the emergency; trained pre-hospital care of the emergency patient within the EMS (Notfallrettung); and the delivery of the emergency patient to the accident and emergency department

21 Rieger (2001) Lexikon des Arztrechts $2^{\text {nd }}$ edition, chapter 4540, margin number 1.

22 Gesetz über den Beruf der Rettungsassistentin und des Rettungsassistenten vom 10.7.1989 BGB1 I 1989, 1384.

23 Ausbildungs- und Prüfungsverordnung für Rettungsassistentinnen und Rettungsassistenten vom 7.11.1989 BGB1 I 1989, 1966.

24 Ratzel and Luxenburger (2008) Handbuch Medizinrecht §23, margin number 1. 
and/or the intensive care unit of the appropriate facility for further medical care. This procedure must be complied with in order to guarantee optimal health care. ${ }^{25}$

Over the last years, EMS have achieved a high standard, performing 10.2 million rescue efforts in 2004 and 2005. These can be divided into 4.7 million emergency operations (Notfalleinsätze) and 5.5 million ambulance visits. Within the scope of emergency operations, the rescue service reaches the scene in an average of 8.1 minutes. ${ }^{26}$

\section{Function and structure of EMS}

As mentioned before the EMS also includes medical services by doctors on call. In order to be able to explain the difference between the EMS and medical services by doctors on call, one has to begin with exemplifying the EMS.

\section{Emergency medical services}

The purpose of the EMS is to guarantee nationwide qualified pre-hospital care and professional ambulance services that are tailored to suit the market need.

\section{a) Duties and responsibilities}

The duties of EMS range from land-based rescue services to air, mountain and water rescue services. ${ }^{27}$ The following explanations refer only to land-based rescue services.

\section{i) Qualified pre-hospital care}

The function of pre-hospital care is to look after emergency patients at the site of the emergency, prepare them for transport to the appropriate facility for further medical care and to take care of them during the trip. It also includes the transport of emergency patients with intensive care conditions to continuing diagnostic accommodation or other adequate institutions for medical care. ${ }^{28}$ Emergency patients are sick or injured people whose lives are in danger or about whom it is feared they will suffer severe damage to their health if they do not receive medical treatment at once. ${ }^{29}$

\section{ii) Professional ambulance services}

The professional ambulance service provides transport for sick and injured people or people in need of help, as well as professional attendance during transport. It can be urgent or scheduled. In the case of urgent transport, every delay endangers the patient's health, even though there need not be a threat to life, for example in the event of im-

25 http://www.gbe-bund.de/gbe10/abrechnung.prc_abr_test_logon? p_uid $=$ gastg\&p_aid $=\& p \_k n o t e n=$

FID\&p_sprache= D\&p_suchstring=1137::Rettungsdienste [last accessed on 15 April 2009].

26 Report of the Federal Government on the provisions to control accidents on the road 2004 and 2005 [Unfallverhütungsbericht Straßenverkehr 2004/2005 vom 28.6.2006] BT-Drucks $16 / 2100,28.6 .2006$, p. 30.

27 Ratzel and Luxenburger op. cit. \$23, margin number 7.

28 Ratzel and Luxenburger op. cit. \$23, margin number 8.

29 Rieger op. cit. chapter 4540, margin number 1. 
minent delivery ${ }^{30}$ The carrying of sick people or people with disabilities who, according to medical judgement, do not need professional medical care during transport is not part of the professional ambulance service. ${ }^{31}$

b) Sponsorship and enforcement

According to the predominant legal implementation in most of the federal states, the rural districts (Landkreise), cities which do not belong to rural districts (kreisfreie Städte), municipalities (Gemeinden) or several local authorities associated in an administrative union (Zweckverband) are the providers (Träger) of the respective EMS. In the federal state of Baden-Württemberg, the Ministry of Social Affairs arranges the enforcement of EMS with aid organisations and other healthcare providers (Leistungserbringer).

Depending on the legal implementation, public providers can assign the enforcement of EMS to aid organisations, professional fire brigades and private companies as far as they fulfil the necessary requirements. In the federal state of Baden-Württemberg, organisations with which the Ministry of Social Affairs has made an arrangement administer the rescue services and also carry out professional ambulance services. In the federal state of Berlin, the municipal fire brigade is the executing institution. However, the tasks of EMS can also be conferred upon aid organisations or other convenient facilities.

Providers have to draw up consumption plans which should not only ascertain the fulfilment of tasks but consider also the principles of thrift and economic efficiency. Health care providers as well as the sponsors (Kostenträger) participate in establishing these plans. A consumption plan determines the facilities, vehicles and posts required. A deadline defining the time in which an emergency services vehicle has to arrive at the scene (rescue time, Hilfsfrist) and the density of population serve as rules. The socalled rescue time comprises the period from the receipt of the emergency call to the arrival of the first appropriate emergency vehicle at the scene. ${ }^{32}$ It is an important quality characteristic, essential for creating the infrastructure and a crucial cost factor: the shorter the rescue time, the more guard-houses, vehicles and personnel must be kept ready. On the other hand, providing emergency patients quickly with medical care at the scene minimises the danger of subsequent damage and, with it, medical costs. Hence, a compromise between what is affordable and what is medically essential must be found. ${ }^{33}$

30 http://www.gbe-bund.de/gbe10/abrechnung.prc_abr_test_logon? p_uid=gastg\&p_aid $=\& p \_$knoten

$=\bar{F}$ ID\&p_sprache $=$ D\&p_suchstring=1137::Rettungsdienste [last accessed on 15 April 2009].

31 Ratzel and Luxenburger op. cit. §23, margin number 10.

32 Unfallverhütungsbericht Straßenverkehr 2004/2005 vom 28.6.2006 op. cit. p. 30.

33 http://www.gbe-bund.de/gbe10/abrechnung.prc_abr_test_logon?

p_uid=gastg\&p_aid $=\& p \_$knoten $=$

FID\&p_sprache=D\&p_suchstring=1137::Rettungsdienste [last accessed on 15 April 2009]. 
The federal state laws on EMS do not define rescue time consistently but, for example, as running time. Correspondingly, the specifications range from 'no time designation' to ' 15 minutes driving time'. ${ }^{34}$

The EMS must provide $95 \%$ of accident scenes with a professional medical vehicle to the street within the respective time limit in order to comply with the rescue time..$^{35}$

\section{Medical services by doctors on call}

Medical services by doctors on call form an independent task within the emergency medical aid sector.

\section{a) Duties and responsibilities}

In co-operation with the personnel, vehicles and equipment of the EMS, medical services by doctors on call should supply emergency patients with the medical attendance of physicians who are specialised in emergency medicine.

Medical services by doctors on call must be distinguished from the emergency services of Statutory Health Insurance-accredited physicians (vertragsärztlicher Notdienst, hereinafter SHI-accredited physicians). ${ }^{36}$ The latter perform their tasks in accordance with the service guarantee of the Association of Statutory Health Insurance Physicians (Sicherstellungsauftrag der Kassenärztlichen Vereinigung). That is to say, they undertake ambulatory care if patients need medical attendance in out-of-surgery hours. This provides the typical services of a practising physician and is not part of the EMS. ${ }^{37}$

\section{b) Sponsorship and enforcement}

Sponsorship and organisation of medical services by doctors on call turn out to be different in particular federal states. The governing bodies of EMS and, to some extent, the Association of Statutory Health Insurance Physicians are obliged to ensure this service..$^{38}$ It is rendered by physicians who are members of the Association of Statutory Health Insurance Physicians. Therefore, the governing bodies of hospitals have to place appropriate physicians at its disposal. Depending on the circumstances, medical practitioners in private practice can also contribute to these medical services. ${ }^{39}$

34 http://www.gbe-bund.de/gbe10/abrechnung.prc_abr_test_logon? p_uid $=$ gastg\&p_aid $=\& p \_$knoten $=$

FID\&p_sprache=D\&p_suchstring=1137::Rettungsdienste [last accessed on 15 April 2009].

35 Ratzel and Luxenburger op. cit. \$23, margin number 10.

36 Statutory Health Insurance Solidarity Empowerment Act (Gesetz zur Stärkung der Solidarität in der gesetzlichen Krankenversicherung, GKV-Solidaritätsstärkungsgesetz), available at: http://www.gesetze-iminternet.de/bundesrecht/gkv-solg/gesamt.pdf [last accessed on 15 April 2009].

37 Ratzel and Luxenburger op. cit. \$23, margin number 14/15.

38 Ibid. \$23, margin number 16.

39 Ibid. §23, margin number 17. 


\section{Costs}

Both the governing bodies and/or the care providers of EMS may impose fees for their services. Sponsors have to agree these fees. Based on an effective organisation, as well as a thrifty and economic management, they are measured to such an extent that they cover the total costs of EMS. ${ }^{40}$

\section{Supervision}

Making sure the tasks of EMS are executed, the competent institutions supervise the health care providers which are instructed to enforce EMS. They are authorised to issue directives to the medical providers. ${ }^{41}$

\section{Approval procedure}

Providing EMS means taking responsibility for the lives and health of injured and sick people who need medical care and emergency transport, so an approval procedure is premised.

\section{Obligation to obtain a permit}

Every organisation seeking to render services within EMS needs approval from the competent institution, unless it is exempted from the obligation to obtain a permit. The same is necessary for expansions and essential modifications of the respective organisations. In most federal states, EMS conferred from the governing bodies to professional health care providers is excluded; ${ }^{42}$ while in some parts it is differentiated in reference to the type of service. The exemption from the duty to obtain a permit does not release an organisation from the commitment to comply with the laws on EMS.

Permission only applies to single vehicles. Until the permit has been granted, the respective vehicle is not an emergency vehicle of the EMS and must not be tooled up with a blue light. Approbation can be subject to certain conditions and sanctions and is restricted in terms of its negotiability. ${ }^{43}$

\section{Licence conditions}

There are various requirements which must be fulfilled in order to gain a permit. The security and capability of the organisation must be guaranteed, the applicant must be suitable for managing it and there must not be any indications of the applicant's untrustworthiness as an entrepreneur. The enterprise itself is trustworthy if one can assume that the people appointed to run the business attend, in doing so, to the regulations of the EMS.

Aptitude is verified by means of passing a test or performing an appropriate activity in an organisation which is focused on the action the subject of the application. 
According to the predominant opinion, approval must be denied if the public interest within the functionality of EMS could be affected by its usage (Funktionsschutzklau$\mathrm{sel}$ ). In this respect, extensive provision and workload within EMS, in particular the number of vehicles and their locations, as well as the development of the profit situation, must be taken into account. An impairment of the public interest exists if the hold-back time exceeds demand. Only if nationwide EMS exists can one refer to this clause. The licence is revocable. ${ }^{44}$

\section{Duties of the entrepreneur}

The entrepreneur has the obligation to set the organisation up properly and maintain it according to the licence (Betriebspflicht). He or she must ensure the accessibility and operational readiness of his firm in hours of operation.

At the request of the rescue co-ordination centre, the enterprise is obliged to utilise its life-saving appliances, provided that the transport starting point lies within its operating range or that the vehicle requested would be the first on the scene (Leistungspflicht). The enterprise cannot decline transportation due to a valid contract being missing or the payment of fees not being secure.

Moreover, the organisation is responsible for personnel receiving continuous education that must be equivalent to the prevailing medical and technical level (Fortbildungspflicht).

\section{Organisation of the emergency medical services}

In order to organise EMS in the most workable way, the appropriate facilities, necessary life-saving appliances and efficient systems of service are indispensable.

\section{Facilities}

The rescue co-ordination centre (Rettungsleitstelle) assumes operational command within the particular departments of EMS. It takes incoming emergency calls which it treats suitably. The rescue co-ordination centre further co-ordinates, controls and supervises the entire process of the several rescue operations. ${ }^{45}$ In this connection, it works together with the respective hospitals, the emergency services of SHI-accredited physicians and the police and fire brigades, as well as other institutions operating in the range of EMS. Moreover, it participates in disaster control. It is essential that the rescue co-ordination centre is manned, ready to operate and accessible all the time.

The rescue co-ordination centre is resourced with non-medical personnel who are subject to different requirements regarding their qualifications. As a general rule, two people must be operating the centre at the same time and at least one of them must be qualified as an emergency medical technician (Rettungsassistent). In addition, awa-

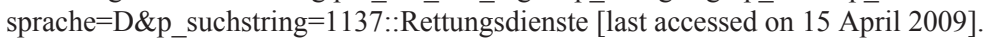


reness of the organisation of EMS and the neighbouring areas, as well as local knowledge, is a precondition.

Ambulance stations (Rettungswache) are organisationally subordinate to the rescue co-ordination centre. They hold essential life-saving appliances and the requisite personnel at the ready. ${ }^{46}$ Their locations are distributed within the department of EMS so as to meet the rescue time and ensure the consistent medical care of the population. ${ }^{47}$

\section{Life-saving appliances}

All EMS vehicles must not only be admitted as an ambulance by means of the vehicle registration certificate but must also measure up to most aspects of the requirements of European standard CEN 1789, as reflected in German standard DIN EN $1789^{48}$ or German standard DIN 75079.49

The patient transport ambulance (Krankentransportwagen) is a vehicle merely equipped for professional ambulance services. It is consistent with DIN EN 1789 type A1/A2.

In comparison, the mobile intensive care unit (Rettungswagen) is used for transport, further medical attendance and the supervision of emergency patients. It conforms to DIN EN 1789 type C.

Rapid response units (Notarzteinsatzfahrzeug) are station wagons or small vans with special equipment capable of transporting an emergency physician and technical facilities to the scene. With regard to equipment and servicing, the vehicles must comply with the generally accepted provisions of emergency medicine and technology. It matches DIN 75079.

Rescue vans staffed merely with an emergency physician and a non-medical driver (Notarztwagen) are also on duty. ${ }^{50}$

Additionally, DIN EN 1789 defines another type of ambulance which is not used in Germany. The emergency ambulance (Notfallkrankenwagen), which corresponds to DIN EN 1789 type B, is designed and equipped for transport, qualified pre-hospital care and the supervision of emergency patients. It must not be mistaken for a multipurpose vehicle (Mehrzweckfahrzeug), which serves a dual role as patient transport vehicle and as backup for emergency responses; this is used in several regions. ${ }^{51}$

Ambulances must be staffed with at least two non-medical people who are both professional and hygienic and who also have to be accurate and dependable at the scene.

46 Ratzel and Luxenburger op. cit. §23, margin number 32 et seq.

47 http://www.gbe-bund.de/gbe10/abrechnung.prc_abr_test_logon?

p_uid=gastg\&p_aid=\&p_knoten $=$ FID\&p_

sprache $=$ D\&p_suchstring $=1137::$ Rettungsdienste [last accessed on 15 April 2009].

48 EN 1789: Medical vehicles and their equipment - road ambulances (Rettungsdienstfahrzeuge und deren Ausrüstung - Krankenkraftwagen).

49 DIN 75079 is a German standard of medical technology which regulates the requirements for mobile intensive care units.

50 Kühn, Luxem and Runggaldier (2007) Rettungsdienst heute $4^{\text {th }}$ edition, p. 723.

51 For further information, see http://www.lrs-baden.de/uploads/media/Normen_01.pdf [last accessed on 15 April 2009]. 
It is important that, as a minimum, one emergency medical technician looks after the patient when transporting him or her to a medical facility. In the case of providing qualified pre-hospital care, it must be a paramedic who is looking after the patient whereas the second person on board needs to be at least an emergency medical technician. Rapid response units are generally staffed with an emergency medical technician. $^{52}$

\section{Systems of services}

With a view to land-based medical services by doctors on call, two strategies in dispatching EMS vehicles can be distinguished: the station system; and the rendezvous system. Eighty seven per cent of all systems are organised as the rendezvous type; $9 \%$ as station systems; and the remainder as hybrid forms. A distinct bias towards the rendezvous type of system has taken place over the past years. ${ }^{53}$

\section{a) Station system}

Within the scope of the station system, one medical care unit staffed with an emergency physician and non-medical personnel travels to the scene. ${ }^{54}$ Having received qualified pre-hospital care in the medical care unit, the patient is transported to an appropriate institution for further medical care, accompanied by the emergency physician. ${ }^{55}$

b) Rendezvous system

The rendezvous system means that, in parallel to an emergency ambulance equipped with non-medical personnel, an emergency physician rides to the scene in a separate vehicle alongside a non-medical driver. ${ }^{56}$ As within the range of the station system, the patient can be escorted by the emergency physician to a convenient institution for further medical care. However, using the rendezvous system, the emergency physician can, as far as medical attendance is not necessary, announce himself ready for further action after providing first aid. ${ }^{57}$

The personnel and their responsibility assignment

One has to distinguish between the medical and non-medical personnel working for EMS. Both medical personnel and non-medical personnel are under an obligation to continue their medical education. ${ }^{58}$

52 Ratzel and Luxenburger op. cit. §23, margin number 36.

53 Kühn, Luxem and Runggaldier op. cit. p. 722.

54 Ibid.p. 722.

55 Ratzel and Luxenburger op. cit. §23, margin number 37.

56 Kühn, Luxem and Runggaldier op. cit. p. 721.

57 Ratzel and Luxenburger op. cit. §23, margin number 37.

58 Ibid. §23, margin number 47. 


\section{Medical personnel}

The medical personnel comprise the doctor on call, the executive doctor on call and the medical executive of the EMS.

a) The doctor on call

Only physicians specially trained for EMS can be appointed as doctors on call (Not$a r z t$ ). The qualifications required carry the title 'emergency medicine', the Certificate of Specialist Training in 'emergency medical services' or a comparable qualification. ${ }^{59}$

The doctor on call is responsible for accomplishing diagnostic and therapeutic tasks in the medical area. His duties are: assessment of the situation; preparing the patient for transport to an appropriate facility; and attending the patient if medically necessary. The doctor on call is the director of operations from the medical-organisational and tactical perspectives, and is authorised to issue medical instructions to staff members. ${ }^{60}$

b) The executive doctor on call

The providers of each EMS department appoint an executive doctor on call (leitender Notarzt). Their function is to govern EMS rescue operations on the spot in the case of major damaging circumstances. Beyond the requirements for doctors on call, executive doctors on call additionally need the Certificate of Specialist Training 'executive doctor on call', an education as an intensive medical care specialist or an equal qualification. Moreover, knowledge of emergency medical aid as well as organisational skills is assumed. ${ }^{61}$

In case of an emergency as a result of which several sick or injured people have to be taken care of, the executive doctor on call is in charge of all medical tasks. He or she has to assure a level of medical care concurrent with the principles of emergency medicine. That is to say, he or she has to assess the situation with regard to the number of sick and injured people, the severity of their impairments to health, any supplementary hazards and the capacity of personnel and materials, as well as secondary treatment options. He or she must further co-ordinate life-saving facilities and their destination according to the specialities and capacities of the particular institution, and requests additional life-saving facilities and personnel if needed. The executive doctor on call is authorised to issue medical-organisational instructions to individual rescue workers. ${ }^{62}$

c) Medical executive of the emergency medical services

The medical executive of EMS is appointed by EMS providers for their particular department. Beyond the requirements for doctors on call, the medical executives of

59 Cf. Rieger op. cit. chapter 4540, margin number 29.

60 Ratzel and Luxenburger op. cit. \$23, margin number 48.

61 Ibid. $\$ 23$, margin number 39.

62 Ibid. \$23, margin number 49. 
EMS also need the Certificate of Specialist Training 'executive doctor on call' or 'medical executive of emergency medical services' or equivalent qualification. ${ }^{63}$

The duties of the medical executive of EMS are to advise and support the EMS provider and to co-ordinate and supervise the activities of the rescue co-ordination centre. He or she is also responsible for the continuing medical education of the personnel. Moreover, he or she has the authorisation to issue medical directives to the personnel participating in rescue operations. ${ }^{64}$

\section{Non-medical personnel}

The non-medical personnel include paramedics, emergency medical technicians, rescue helpers and ambulance personnel respectively. They can be combined as a rescue team (Rettungsteam). What is more, the personnel of the rescue co-ordination centre perform essential tasks within EMS.

\section{a) Requirements for non-medical professions}

In order to work for EMS as a paramedic, an emergency medical technician or a rescue helper, an individual must have received a professional education. However, only a paramedic apprenticeship counts as a recognised trade. ${ }^{65}$

\section{i) Paramedics}

An apprenticeship as a paramedic (Rettungsassistent) is regulated in the Rettungsassistentengesetz. Pursuant to $§ 2(1)(1)$, the permit to hold this occupational title is granted upon request if the applicant has participated in an annual training course (1 200 hours), passed the state examination and successfully fulfilled the practical exercise (1 600 hours). The candidate should not behave in such a manner as if he or she was unreliable to hold this profession $(\S 2(1)(2)$ RettAssG). Furthermore, he or she must not be hygienically unfit to work as a paramedic $(\S 2(1)(3)$ RettAssG).

With regard to the duration of the training course and the practical exercise, other apprenticeships can be taken into account. In particular, training as an emergency medical technician (Rettungssanitäter) must be considered (cf. §8(2) RettAssG). ${ }^{66}$

\section{ii) Emergency medical technicians}

The 520 hours 'rescue' programme of the Committee of the Federation and the Federal States $^{67}$ is relevant to the apprenticeship of an emergency medical technician. Accordingly, 160 hours of theoretical and practical lessons at a special school (Rettungsschule), 160 hours of clinical training in a convenient hospital and 160 hours of practical education at a state-registered training school must be passed. The final state exami-

63

\$23, margin number 50

65 Kühn, Luxem and Runggaldier op. cit. p. 903.

66 Ibid. p. 887.

67520 Stunden-Programm des Bund-Länder-Ausschusses „Rettungswesen“ vom 20.9.1977 available at: http://www.asb-hamburg.de/fix/doc/bfs-520stunden-abkommen.pdf [last accessed on 15 April 2009]. 
nation takes place within a 40-hour course of studies. A qualification in first aid dated no longer than one year old is required to participate. ${ }^{68}$

iii) Rescue helpers/ambulance personnel

The apprenticeship of rescue helpers (Rettungshelfer) and ambulance personnel ( $\mathrm{Sa}$ nitätshelfer) conforms to the training guidelines of the aid organisation and does not orient itself towards EMS: a supplementary education is needed as a rule when it comes to EMS.

A qualification as rescue helper allows the individual to be a driver of a patient transport ambulance in several federal states, so the major aid organisations have come to an agreement that the period of education should comprise 320 hours. ${ }^{69}$

b) The duties of a team of rescuers

A paramedic performs life-saving measures until a physician takes over medical treatment and, after that, provides further assistance. ${ }^{70} \mathrm{He}$ or she further prepares patients for transportation, monitors and sustains their vital bodily functions and transports needy people even if they are not emergency patients ( $\$ 3$ RettAssG). Emergency medical technicians support the emergency physicians and paramedics.

Non-medical personnel do not have the authorisation to perform medical tasks independently. Nevertheless, an emergency physician is not always at the scene (on time), so non-medical personnel are allowed to execute advanced life-saving measures within a so-called state of emergency (Notstandslage). An obligation to act can follow from such that waiting for an emergency physician would be an insufficient response. ${ }^{71}$

There is no legal provision regulating the measures allowed within a state of emergency, so the German Medical Association (Bundesärztekammer) has published a statement on the competencies of paramedics in emergency situations. ${ }^{72}$

c) The personnel of the rescue co-ordination centre

The rescue co-ordination centre answers incoming emergency calls and other requests for help, and arranges the necessary measures. The centre has power of decision-making in view of the number and type of life-saving measures which should be utilised. Together with the emergency physician and the non-medical personnel, it determines the destination of the transport vehicles and registers the patient with the respective institution. It is authorised to issue directives to the personnel other than medical decisions, which remain the preserve of the emergency physician. Moreover, the rescue co-ordi-

68 Kühn, Luxem and Runggaldier op. cit. p. 890.

69 Ibid. p. 890.

70 Ibid. p. 912 and p. 914.

71 Ratzel and Luxenburger op. cit. §23, margin number 53.

72 Stellungnahme zur Notkompetenz von Rettungsassistenten und Delegation ärztlicher Leistungen im Rettungsdienst, available at: http://www.bundesaerztekammer.de/page.asp? his $=1.306 .5935 .5938$ [last accessed on 15 April 2009]. 
nation centre can charge the providers of neighbouring departments and enforcement facilities with reciprocal support. ${ }^{73}$

What is more, the centre conveys medical help to the caller by phone and can instruct them to perform life-saving measures on the spot. ${ }^{74}$

\section{Concluding statement}

It can be seen that, in the Federal Republic of Germany, a very detailed and sophisticated legislation on EMS is valid. Not only are the organisation and conduct of EMS regulated very thoroughly, but the personnel with whom emergency vehicles are staffed stem from particular rules. Every staff member, whether a part of medical or non-medical personnel, needs certain qualifications and requires special training in order to work for EMS. In addition, not everyone is allowed to render services within EMS; in a few cases, approval from a competent institution is needed. An EMS system as organised and thought-out as the one described ensures a high quality standard which becomes apparent when contemplating the average rescue time of 8.1 minutes.

Notwithstanding, the German system (applying the Franco-German model) has its disadvantages. Due to the disproportionate rise in expenditure, EMS has been heavily criticised in the last few years. Health care providers, rural districts and cities which do not belong to rural districts are blamed for economic inefficiency and a lack of a preparedness to accommodate competition. ${ }^{75}$

\section{EU legal standards on emergency medical services}

In order to analyse whether the Serbian legislation complies with European requirements, one has first to explore the EU legal standards on emergency medical services.

\section{Competences of the European Community in the range of health care}

Public health constitutes a separate title within the third part of the TEC (Treaty establishing the European Community, hereinafter TEC) which is devoted to 'the policies of the Community'. Nevertheless, the competences of the European Community (EC) within the scope of health care are limited. ${ }^{76}$

73 Ratzel and Luxenburger op. cit. §23, margin number 56 et seq.

74 Ibid. \$23, margin number 57.

75 http://www.gbe-bund.de/gbe10/abrechnung.prc_abr_test_logon? p_uid $=$ gastg $\& p \_a i d=\& p \_k n o t e n=F I D \& p$ sprache=D\&p_suchstring $=1137::$ Rettungsdienste [last accessed on 15 April 2009].

76 Callies and Ruffert-Wichert (2007) EUV/EGV Kommentar $3^{\text {rd }}$ edition, Art. 152, margin number 2 . 


\section{The contribution of the European Community towards health care}

In accordance with Article 3(1)(p) of the TEC, the activity of the European Community includes a contribution towards the attainment of a high level of health protection. ${ }^{77}$ That is to say, the EC does not pursue an autonomous health care policy but confines itself to this level of participation. On the one hand, the EC makes a contribution to the health care policies of member states on the basis of Article 152 of the TEC ('vertical'); and, on the other, outside of Article 152 of the TEC, in connection with other Community policies ('horizontal'). ${ }^{78}$

The result is that there is no health care policy of the EC as such, but health care policies (of the EC and the member states), within Article 152 of the TEC, thereby have the function of a switch point in service of the purpose predefined by Article 3(10)(p) of the TEC: it enables the EC to produce consistency between the health care policies of member states while obliging it to consider the horizontal consistency of its own measures relevant to health issues. ${ }^{79}$

\section{Authorisation to act and possible forms of action}

Despite the wide sphere of activity in the area of 'public health', and despite the ambitious goal of attaining a high standard of health protection concerning all policies, Article 152(1)(2) of the TEC explicitly determines the Community to making no more than a supplementary contribution towards achieving this purpose. Hence, public health is an area of mixed competences. Owing to the principle of subsidiarity determined in Article 5 of the TEC, the primary accountability for health care as a whole remains with the member states. ${ }^{80}$

The supplementary activity of the EC ranges between co-ordination, co-operation with third parties, encouragement and recommendations (cf. Art. 152, sections 2-4) and can cover the whole spectrum of public health. As far as using legislative forms of action, such as directives or regulations, the competences of the Community are restricted to measures setting high standards of quality and the safety of organs and substances of human origin, blood and blood derivatives (Art. 152(4)(a)); and measures in the veterinary and phytosanitary fields which have as their direct objective the protection of public health (Art. 152(4)(b)). ${ }^{81}$

However, pursuant to Article 152(5) of the TEC, the organisation of public health and medical care are clearly excluded and, therefore, remain within the responsibility of the member states. Notwithstanding this, other provisions of the TEC - such as, for example, the general non-discrimination rule (Art. 12(1)) and the fundamental freedoms (or, if the providers are entrepreneurs according to Art. 81, competition law) -

77 Von der Groeben, Schwarze, Bardenhewer-Rating and Niggemeier (2003) Kommentar zum Vertrag über die Europäische Union und zur Gründung der Europäischen Gemeinschaft $6^{\text {th }}$ edition, Art. 152, margin number 1.

78 Callies and Ruffert-Wichert op. cit. Art. 152, margin number 2.

79 Ibid. Art. 152, margin number 3.

80 Von der Groeben, Schwarze, Bardenhewer-Rating and Niggemeier op. cit. Art. 152, margin number 8 .

81 Ibid. Art. 152, margin number 9. 
can take effects on state health care systems. The result is that the EC already exerts influence on the health care systems of member states on a big scale. ${ }^{82}$ At this point, one has also to consider that Article 95 of the TEC offers the possibility of enacting directives which can influence state health care systems. One example is EU Directive 93/42/EEC ${ }^{83}$ concerning medical devices.

\section{Emergency medical services in Europe}

Europe-wide standards exist relating to many different topics. Standards are documented, constituting voluntary agreements within which important criteria for products, services and procedures are determined. Standards contribute to health protection, security and the environment of European citizens. They lend to technical problem solving and also facilitate trade and co-operation within the EU. ${ }^{84}$

\section{The European Committee for Standardisation}

With the establishment of European Committee for Standardisation (CEN) 'TC 239 Rescue Systems' commenced the consolidation of the different requirement profiles of life-saving appliances in the member states of the European Union. CEN-TC 239 has the mandate of standardising the different medical-technical equipment and vehicles of EMS. ${ }^{85}$ The initiative for its foundation sprang from the Federal Republic of Germany, so the direction of its secretariat rests with the German Institute for Standardisation, the Deutsches Institut für Normung (DIN). ${ }^{86}$

European Standard CEN-TC 239 was prepared under a mandate given to CEN by the European Commission and the European Free Trade Association, and supports the essential requirements of the above-mentioned EU directive 93/42/EEC. The legal foundation of EU directive 93/42/EEC, which was revised by EU directive 2007/47/

82 Callies and Ruffert-Wichert op. cit. Art. 152, margin number 8.

83 Council Directive 93/42/EEC of 14 June 1993 concerning medical devices, available at: http:// eur-lex.europa.eu/LexUriServ/LexUriServ.do?uri=CELEX:31993L0042:EN:HTML [last accessed on 15 April 2009].

84 Normung in Europa http://ec.europa.eu/enterprise/standards_policy/european/flyer/de.pdf [last accessed on 15 April 2009].

85 For a review of published standards, see: http://www.cen.eu/CENORM/Sectors/TechnicalCommitteesWorkshops/CENTechnicalCommittees/Standards.ap?param $=6220 \&$ title $=\mathrm{CEN} \% 2 \mathrm{FTC}+239$ [last accessed on 15 April 2009]. A review of standards under development is available at: http://www.cen.eu/CENORM/Sectors/TechnicalCommitteesWorkshops/CENTechnicalCommittees/WP.asp?param=6220\&title $=$ CEN\%2FTC +239 [last accessed on 15 April 2009].

86 http://www.lrs-baden.de/uploads/media/Normen_01.pdf [last accessed on 15 April 2009]. 
EC, ${ }^{87}$ is the TEC and, in particular, its Article 95. ${ }^{8889}$ As stated in the preamble, the use of medical devices needed to be harmonised by means of the directive so as to guarantee free movement within the internal market. ${ }^{90}$

Europe-wide standards in the range of emergency medical services

The most important European standard in the range of EMS might be CEN 1789, determining the requirements for medical vehicles and their equipment, as explained above.

Another European standard is CEN 1865, which defines the specifications for stretchers and other patient-handling equipment used in road ambulances.

Moreover, there are European-wide standards for duty gear, which serves the selfpreservation and perceptibility of personnel. ${ }^{91}$

\section{Other agreements}

It was agreed that ' 112 ' would be the Europe-wide emergency telephone code for all types of request for help. ${ }^{92}$

There are no European standards for the fulfilment of particular rescue times. At best, there are recommendations for complying with a rescue time of between ten and twenty minutes. However, member states can modify this limit upwards or downwards.

Some EMS organisations are qualified by European quality management standards. These organisations thereby guarantee to fulfil a particular standard that ranges from the sourcing of material to attendance on a patient.

\section{Evaluation of the Serbian legislation and comparative analysis}

There are three issues by means of which one can specifically compare the Serbian legislation on EMS to the described legislation of the Federal Republic of Germany. These are: the organisation of EMS; the apprenticeship of the staff working for EMS; and the requirements for rendering services within EMS.

87 Council Directive 2007/47/EC of the European Parliament and of the Council of 5 September 2007, available at:

http://eur-lex.europa.eu/LexUriServ/LexUriServ.do?uri=OJ:L:

2007:247:0021:0055:EN:PDF [last accessed on 15 April 2009].

88 Article 95 of the TEC is the former Article 100 of the Treaty establishing the European Economic Community, cited by directive 93/42/EEC.

89 Cf. Explanatory statement of Council Directive 2007/47/EC of the European Parliament and of the Council of 5 September 2007, available at:

http://eur-lex.europa.eu/LexUriServ/LexUriServ.do?uri=OJ:L:

2007:247:0021:0055:EN:PDF [last accessed on 15 April 2009.

90 Ibid.

91 A list of all standards concerning duty gear is imprinted in: Berghaus and Langner Das CE Zeichen part 2, stand 2008.

92 For further information, see: http://www.evz.de/UNIQ123917808831548/doc1160A.html [last accessed on 15 April 2009]. 


\section{Organisation of the emergency medical services}

Regulations concerning the organisation of EMS can be found in the HCL as well as the Network plan for health institutions. Even so, there is neither a specific law nor a particular chapter within one of these acts that deals exclusively with the organisation of EMS. The existing regulation gives attention to EMC only by means of articles (paragraphs) or provisions.

However, HCL and the Network Plan both talk about EMC being performed by PHCCs (and some of its external units: branches and local clinics) and IEMCs. It is at any rate advantageous to have provisions determining which institutes are responsible to provide EMS. All the same, it would be of great advantage to have one central organisation that allocates emergency cases to the appropriate health care institutions. Thereby, one can avoid unnecessary problems, such as questions of the availability and responsibility of particular health institutions in a particular situation. Such a central organisation does exist in Germany: the rescue co-ordination centre responds to emergency calls and co-ordinates, controls and supervises the entire process of diverse rescue operations. It further works, together with the respective hospitals, in order validly to administer the hospital assignment of emergency patients. Hence, patients are allocated according to an optimal use of the capacity of hospitals or to their possible pretreatment in hospital.

In contrast to the Republic of Serbia, EMS in Germany has its own facilities and life-saving appliances, as well as different systems of services which are executed depending on the emergency case at hand. There are rules on emergency vehicles and the standards with which they have to comply. The German legislation very thoroughly defines how EMS should be organised; thus it reveals the importance that is attached to EMS and further shows that EMS is acknowledged as an independent service as well as a specialisation in the field of medical care.

\section{Apprenticeship}

The German EMS sets a high value on the training of the personnel employed by particular emergency services. There are specific laws on the apprenticeship of non-medical personnel, such as emergency medical technicians and paramedics. In accordance with them, to be admitted to work for EMS one has to comply with certain requirements, undergo theoretical education as well as practical training, and pass final examinations. What is more, physicians who want to become doctors on call in Germany do not only need managerial skills but also supplementary expertise. Additional titles as 'emergency medicine' and Certificates of Specialist Training in 'emergency medical services' or comparable qualifications are premised. Furthermore, medical personnel as well as non-medical personnel are under an obligation to continue their medical education.

In Serbia, some medical specialities of physicians require knowledge of EMC, but these requirements only refer to health workers not to medical associates. In addition to the basically-required knowledge of EMC, the Rule book on specialisations and advanced specialisations of health workers and medical associates regulates that medical doctors can specialise in the area of emergency medicine. The same rule book 
regulates that specialists in general surgery can study further to acquire a specialisation in emergency surgery.

Emergency situations cannot be compared to the everyday situations that physicians and medical associates experience. It is therefore advisable either to provide additional courses for medical associates who want to work for EMS or to develop specific professions, like paramedic or emergency medical technician, as in Germany. Medical associates should not only have the opportunity but the obligation to specialise and continue their studies in the field of EMS so as to work within this medical area.

As for physicians, they must acquire special education or training in emergency medical aid in order to qualify as emergency physicians. Furthermore, it is of great importance that they have organisational as well as leadership skills since they need to have an overview of the emergency situation and perhaps give medical advice to medical associates. The possibility of specialising in the area of emergency medicine, as set out in Serbia, is therefore indispensable and should be a standing requirement to work in the area of EMS at all.

Naturally, thoroughly educated and trained personnel, who are also prepared for unexpected emergency situations, are the essential foundation of an efficient EMS.

\section{Requirements for rendering services within emergency medical services}

In Serbia, only health institutions are authorised, under certain conditions, to perform EMS as a health activity. Even though obliged to provide urgent medical help to citizens when needed, private practices are neither allowed to perform EMS nor to register to carry it out. In comparison with a system where private EMS is common, one can see the advantage of this regulation. Private firms may, generally speaking, have better availability during the week as well as qualified paramedics with a wide range of skills, but a system of private ambulances is more difficult to regulate. That is to say, a risk regarding the qualification and experience of staff does exist.

In the event of private EMS being requested, one can diminish this risk by an approval procedure or specific standards that must be complied with. Such an approval procedure exists in Germany, under which everyone who wants to render services within EMS needs permission from the competent institution unless he or she is specifically exempted from having to do so.

\section{Compliance of the Serbian legislation on emergency medical services with EU regulations}

As we have explained, there are plenty of European standards concerning EMS. However, these only concern requirements for medical vehicles and their equipment, specifications for stretchers and other patient handling equipment used in road ambulances, and standards for duty gear.

There are rules defining the detailed conditions relating to personnel, equipment, facilities and medicines that need to be fulfilled by health institutions but, in order to perform health care activities, the legal provisions governing specifically EMS in Serbia need to be regulated in more detail. The Special Working Group for Urgent Medicine is the appropriate organisation to establish or regulate such greater detailed stan- 
dards, in line with its consultative activities in the area of emergency medicine. This institution is a step in the right direction.

One should think further of having one standard emergency telephone code for all types of requests for help, comparable to the Europe-wide emergency telephone code ' 112 ' which has already been agreed upon.

Even though there are only recommendations, but no obligatory standards, towards complying with a rescue time of ten to twenty minutes, these should be taken seriously. The Rule book on quality criteria, which prescribes the obligatory and recommended criteria for EMC, reveals the value that is attached to the rapidity and efficiency of each emergency assignment. In order to prove whether these indicators have been followed, it is very useful that the quality criteria of each operational tour are collected and analysed by the Special Working Group for Urgent Medicine of the Republic of Serbia.

\section{Conclusion on Serbian legislation on emergency medical services}

EMS in the Republic of Serbia is regulated in different places and at different levels of Serbian legal regulations. This would not be a disadvantage if these regulations followed each other in a systematic fashion. However, the regulations are quite fragmented. The laws and sub-laws are not bad per se, but show that EMC has not received the attention it deserves and is being treated as a marginal health issue. The lack of the required level of regulation exists in the organisational part of the laws and sub-laws, as well as in that part that relates to the education of specialists in the area of emergency medicine.

In the organisational sense, HCL and the Network Plan should be in greater compliance with the structure of PHCC units that carry out EMC, but also with the departments that carry out EMC at the secondary and tertiary levels. However, instead of making aesthetic changes to the existing regulations, it would be more useful to amend HCL with a specific part related to EMC. EMC also deserves a special, separate rule book, regulating it as a separate, independent service having several levels of action. Namely, EMC constitutes the primary and urgent help provided to a patient in a life threatening situation. EMC is also the last barrier before sending a patient to a health institution. That is why EMC should be established as a specialised, autonomous health service, carrying out its activities at the level of primary health care.

As regards training, the legal regulations should strongly emphasise specialisation in the area of emergency medicine, which would result in the most competent medical team, with adequate medical equipment and transport, first reaching the endangered patient in the shortest period of time. A well-organised EMS, with a specialist in emergency medicine on the scene, should bring about the consequence that only patients who are in real need of hospital diagnostic-therapeutic procedures are transported to the hospital. Hence, before they autonomously work within EMS, all physicians and medical associates should be specially trained in the area of emergency medicine (via theory, participation in expert conferences and continuous education). Therefore, when making plans for legal revisions, the possibilities of specialisation in the area of emergency medicine should be approved. 